\title{
EXPERIMENTAL STUDY OF VIBRATION SIGNATURE OF VARIOUS COUPLINGS USING MFS LITE
}

\author{
Mr. Danish Imam \\ Department of M.E \\ Al-Falah University, Dhauj, Haryana
}

\author{
Mr. Mohd Abbas \\ Department of M.E \\ Al-Falah University, Dhauj, Haryana
}

\author{
Dr. Ahmad Ali Khan \\ Department of M.E \\ A.M.U, Aligarh
}

\begin{abstract}
Misalignment is considered as the second most prevalent vibration source after unbalance. A misaligned rotor always causes more vibration and generates excessive force in the bearing area which reduces the life of machine. Couplings are widely used because of their ability to transmit torque from driving to driven shaft and their consequent ability to compensate misalignment. This work addresses the problem of condition monitoring of mechanical faults due to misalignment. We studied and observed the vibration signatures of two different coupling types and the affect of increased shaft speed on rotor vibration at driving and non driving end. A signal based approach was chosen by using machinery fault simulator with the help of Vibra-Quest software package and with $2 \mathrm{X}$ amplitude 3.78 and 4.01 at $10 \mathrm{~Hz}, 25.5$ and 29.36 at 15 $\mathrm{Hz}, 20.0$ and 24.1 at $20 \mathrm{~Hz}$ on driving and Non driving end respectively, Beam Coupling was concluded to be the most suitable for the said condition for minimal vibration in context with parallel misalignment while the other was showing much higher vibration amplitudes.
\end{abstract}

Keywords: MFS-LITE, Vibration, Coupling, Misalignment, Vibra-Quest

\section{INTRODUCTION}

Rotor shaft misalignment is the common problem in the operation of rotating machinery in any industry. Yet, it remains incompletely understood. Despite the rapid increase in understanding of rotor dynamics, no satisfactory analysis explains the range of observed phenomenon. Considering the importance of the misalignment in the shaft, detecting and diagnosing the misalignment is still elusive. Vibration in rotating machine is generally caused by unbalance, misalignment, mechanical looseness, shaft crack, and many other malfunctions. Misalignment is all thanks to improper machine assembly and generally thermal distortion of the bearing housing supports leading to abnormal rotating preload. "Perfect alignment" of the shafts i.e driving and driven shafts can't be achieved in day to day practical applications. Thus, a misalignment condition is virtually always present in machine-trains. Therefore, a flexible mechanical connector suitable for transmitting rotary power without torsional slip and capable of accommodating unavoidable misalignment must be used. Misalignment is perhaps the foremost common reason behind machinery malfunction. It is easy to understand that misalignment produces high vibration levels in the bearings it's powerfully influenced by machine speed and stiffness of the coupling. Softer coupling are more forgiving, and have a tendency to supply terribly less quantity of vibration levels. A point vibration spectrum for a given operating speed does not provide a good indication of misalignment. Vibration due to misalignment is usually characterized by a $2 \mathrm{X}$ or $3 \mathrm{X}$ running speed component and high axial vibration levels. The simulator is an ideal tool to use for studying the vibration signature that occurs when two mating shaft are misaligned. Hence it is a valuable instrument for conducting routine test on alignment including misalignment of shaft through coupling. Lees et al. (2007) studied the effect of misalignment in rigidly coupled rotors. Dewell and Mitchel et al.(1984) determined the expected vibration frequencies for a misaligned metallic disc flexible coupling. Further, they showed experimentally that the $2 x$ and $3 x$ running speed components show the largest changes as misalignment increases. Woodcock et al.(1977) made an attempt to identify and quantify the main factors which influence the lateral vibration of machine and to produce guidance for coupling selection based on some factors. Pandey and Nakra et al.(2011) provide a valuable information regarding symptoms of machinery failure. Ronak Prajapati and Dr. Anand Parey et al.(2016) found and commented on the misalignment vibration pattern in couplings. In all cases amplitudes are higher at NDE and lesser at DE.

\section{PROBLEM DESCRIPTION}

In today's industrial environment, where equipment system designers are demanding higher speeds, higher torques, 


\section{International Journal of Engineering Applied Sciences and Technology, 2019 \\ Vol. 4, Issue 1, ISSN No. 2455-2143, Pages 86-93 \\ Published Online May 2019 in IJEAST (http://www.ijeast.com)}

greater flexibility, additional misalignment, and lighter weights for flexible couplings. The need for flexible couplings is becoming more acute as is the need for technological improvements in them.

Flexible couplings expand upon the basic function by also accommodating misalignment and end movement. During the initial assembly and installation of rotating equipment, precise alignment of the equipment shaft axes is not only difficult to achieve, but in most cases it is economically prohibitive. In addition, misalignment during equipment operation is even more difficult to control. A flexible coupling serves as a means to compensate for, or minimize the effects of, misalignment. Flexible couplings, however, have their own limitations. Therefore, calculations and predictions are required to know what the maximum excursions can be. Only then can the correct coupling be selected. A system designer or coupling user cannot just put any coupling into a system and hope it will work. It is the responsibility of the designer or user to select a compatible coupling for the system. The designer must also be the coupling selector. Coupling manufacturers are not system designers and should not be expected to assume the role of coupling selectors. The purpose of this project work is to aid the coupling selector (system designer or user) in understanding couplings so the best coupling can be selected for each system.

\section{THEORY}

\section{A. Couplings}

Mechanical element that couples two drive components which enables motion to be transferred from one component to another. The drive components are generally shafts. As with all mechanical devices, a coupling should match its supposed purpose and application parameters together with many alternative performance and application, environmental use and service factors, all must be satisfied for the coupling to work properly. When selected with the above concerned design parameters, and installed and operating correctly, a coupling should have no issues in its lifetime. However, when one or more of these is not met a coupling can prematurely fail, resulting in either machine failure or injury to the operator of the coupled machine.

Shaft couplings are used in machinery for several purposes. A basic function of coupling is to transfer power from one end to another end.

Types of Coupling:

1. Rigid coupling: Rigid couplings ought to solely be used once the connecting structures and instrumentality area unit are rigid enough so that little or no placement will occur and also the instrumentality is powerful enough to just accept the generated moments and force. Eg: Sleeve or muff coupling, Clamp or split-muff or compression coupling and Flange coupling.

2. Flexible coupling: Flexible couplings are designed to transmit torque while permitting some radial, axial, and angular misalignment. Flexible couplings can accommodate significant misalignment up to a few degrees in angular and some parallel misalignment. As flexible couplings accommodate misalignment in a bending mode, reaction is proportional to the flexing member thickness. It is used to connect two shafts having both lateral and angular misalignments. Eg: Bushed pin type coupling, Universal coupling, and Oldham coupling.

\section{B. SHAFT MISALIGNMENT}

The resulting fault if alignment is not achieved within the demanded specifications is shaft misalignment, which may be parallel, angular, or both. Misalignment can cause increased vibration and greater loads on the machine parts than the one they were designed for. (i.e. improper operation).

Types of Misalignment:

1. Parallel Misalignment: Parallel Misalignment occurs when the shaft centre lines are parallel, but are offset from each other. The centrelines may be offset horizontally, vertically or a combination of the two.

2. Angular Misalignment: Angular misalignment can be further subcategorized as either horizontal or vertical misalignment. Angular horizontal misalignment happens when the motor shaft is at an angular displacement with the pump shaft, but both shafts still operate in the same horizontal plane. Angular vertical misalignment happens when the motor shaft is at an angular difference with the pump shaft, but both shafts still operate in the same vertical plane. The most common vibration amplitude, due misalignment, is at a vibration frequency of 2X RPM.

\section{MACHINERY FAULT SIMULATOR}

Spectra Quest's Machinery Fault Simulator - LITE (MFSLT) (Figure 2 (a)) is an innovative tool to study the signatures of common machinery faults without compromising production schedule or profits. The benchtop system features a spacious modular design that includes versatility, operational simplicity, and robustness. Every element is machined to high tolerances thus it is operated while not conflicting vibration. Then, various faults can be introduced either individually or jointly in a totally controlled environment, making the MFS-LT a good tool for learning machinery diagnosis. The MFS-LT is easily operational and designed to be versatile. The simulator is constructed with a split bracket bearing housing, a sliding shaft and rotors with split collar ends and couplings; all of which are designed 


\section{International Journal of Engineering Applied Sciences and Technology, 2019 \\ Vol. 4, Issue 1, ISSN No. 2455-2143, Pages 86-93 \\ Published Online May 2019 in IJEAST (http://www.ijeast.com)}

to be easily removed and replaced between various experiments.

The features of MFS-LT are as follows:

- Simple methods for introducing controlled and calibrated faults.

- Study of the vibrations spectrum of common faults and learning fault signatures.

- Bench top machine for hands-on training and skill sharpening.

- Learn machine condition monitoring and predictive maintenance

- Learn resonance and variable speed diagnostics.

- Learn to perform root-cause analysis and determine vibration transmission path.

- Validate balancing procedures above and below the first critical resonance.

Using the Simulator offers you a wide range of benefits in developing you understanding of predictive maintenance and learning to recognize the signatures of various machine faults. Different types of studies can be done with application specific kits. Each kit is designed to fit on the basic simulator. Application notes and exercises provide a cost effective self-paced training program.

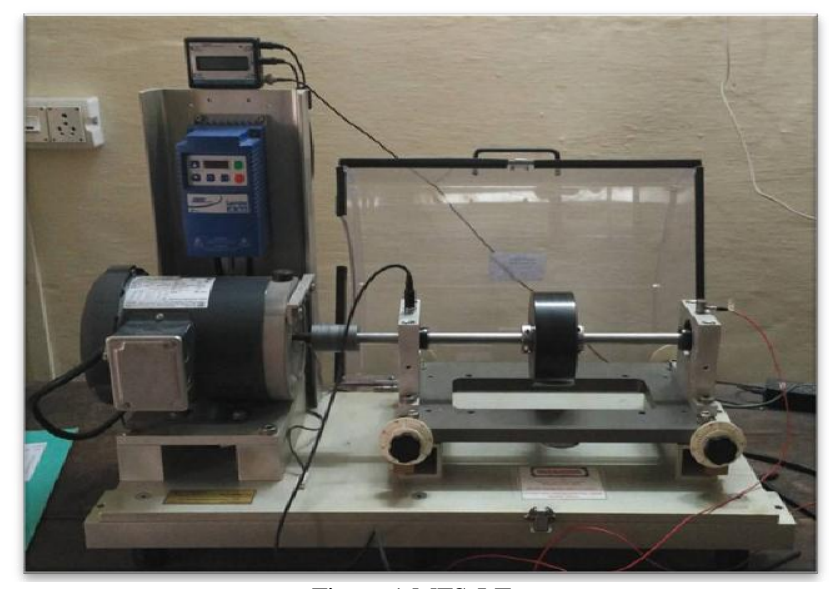

Figure 1 MFS-LT

\section{VIBRA-QUEST}

An innovative data acquisition and analysis tool for noise and vibration (Figure 2 (b)). Vibra-Quest(VQ) is an integrated solutions package for rotating/reciprocating machinery fault diagnosis, structural dynamics analysis and design, and acoustical analysis. It provides tools to solve vibration and noise problems, from experimental design to solution strategy development.

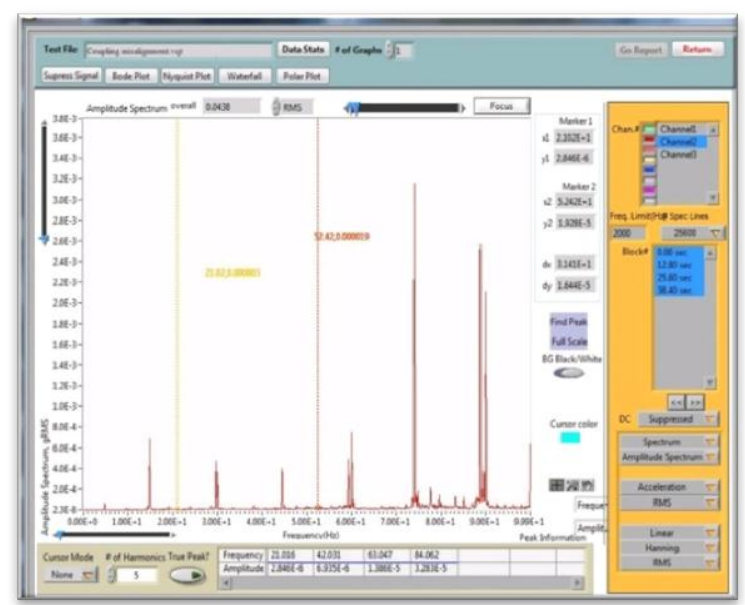

Figure 2Vibra-Quest Interface

\section{EXPERIMENTAL SETUP}

The experimental setup that is employed in this study is shown in Figure 3. This apparatus is driven by a 3-HP induction motor with a speed range between 20 and 4200rpm. The shaft rotation speed can be controlled by a speed controller. An optical sensor is used for shaft-speed measurement. A coupling is utilized to damp out the highfrequency vibration that was generated by the motor. Two rolling-element bearings are fitted in the solid housings. Accelerometers are mounted on the housing of the tested bearing to measure the vibration signals. Transverse signal that was vertically measured is utilized for analysis in this study. Radial load is provided by $12 \mathrm{lb}$. (5.44 kg) loader as shown in Figure above and below.

The test was done with two types of coupling which are as follows:

1. Beam Coupling (Flexible Type).

2. Split Muff Coupling (Rigid Type).

The name and purpose of each part in their numerical order as indicated in figure is as follows:

1. Digital Display Tachometer: To measure and indicate the running speed of rotor.

2. Variable Speed Controller: To control the speed of rotor.

3. Induction Motor: An electric motor which produces torque.

4. Couplings: To transmit the motion from driver shaft to other shaft.

5. ICP Accelerometer: A sensor which convert acceleration into an electrical output.

6. Bearing Housing: To provide support to the shaft consists of bearing and other accessories. 


\section{International Journal of Engineering Applied Sciences and Technology, 2019 Vol. 4, Issue 1, ISSN No. 2455-2143, Pages 86-93 \\ Published Online May 2019 in IJEAST (http://www.ijeast.com)}

7. Rolling Element Bearing: To carry shaft onto the bearing housing by placing balls between two rings.

8. Hardened Shaft: A machine element which rotates and transmit the motion.

9. Loader (12lb): A load to provide practical situation.

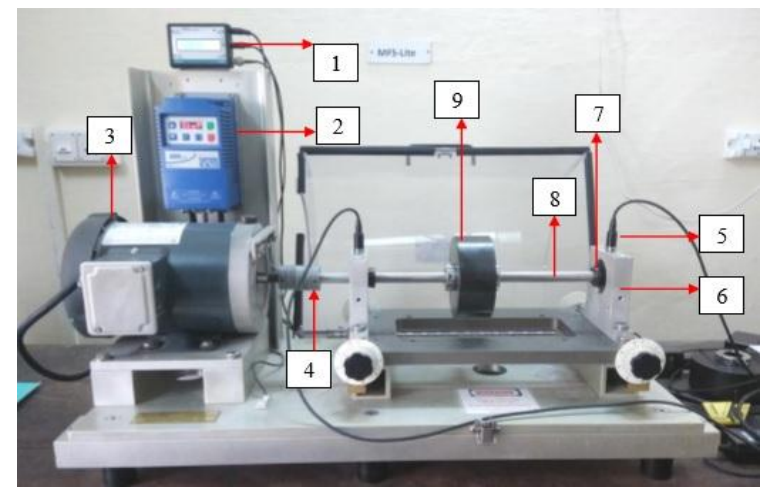

(a) MFSLT

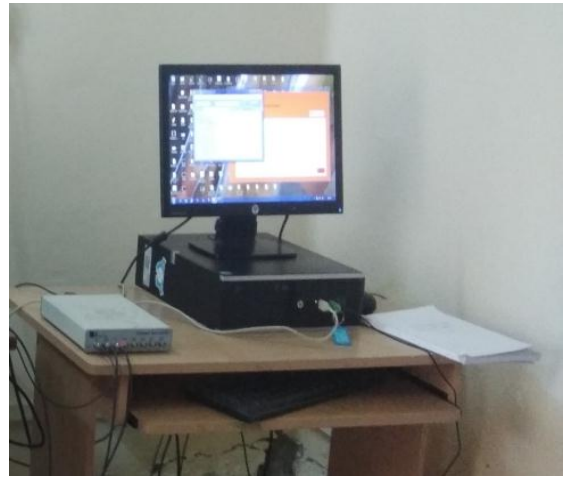

(b) $\mathrm{DAC} \& \mathrm{PC}$

Figure 3 Experimental Setup

The Experiment included recording of driving as well as non-driving end vibrations with both the coupling.

\section{RESULTS}

\section{A. Vibration Spectrum at $10 \mathrm{~Hz}$.}

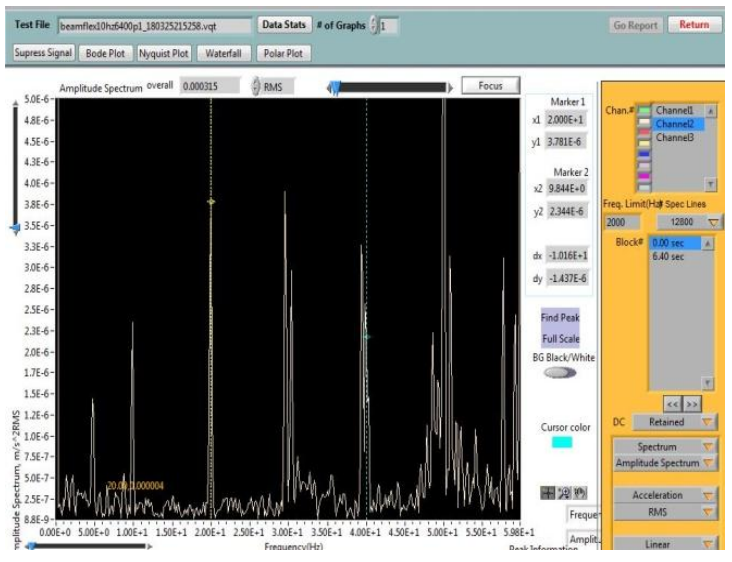

(i) Driving End

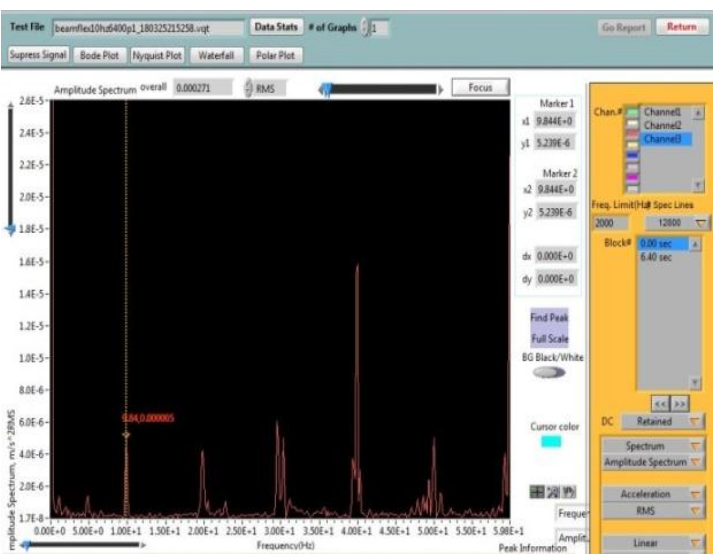

(ii) Non Driving End

(a) Beam Coupling vibration spectrum

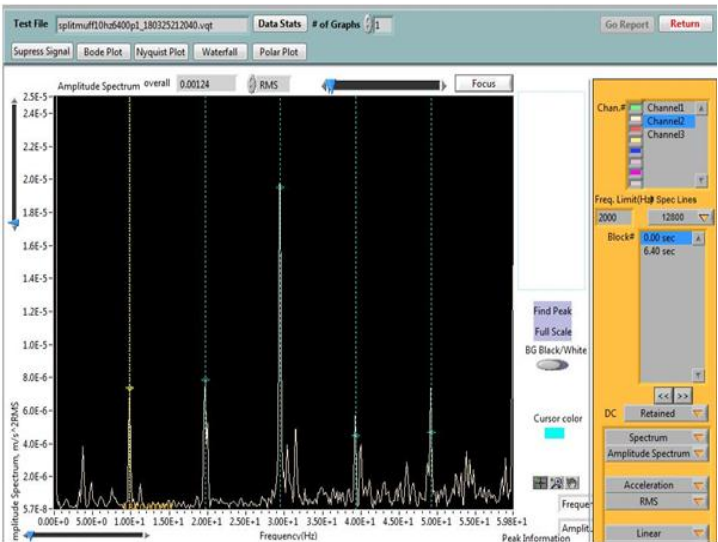

(i) Driving End 
International Journal of Engineering Applied Sciences and Technology, 2019

Vol. 4, Issue 1, ISSN No. 2455-2143, Pages 86-93

Published Online May 2019 in IJEAST (http://www.ijeast.com)

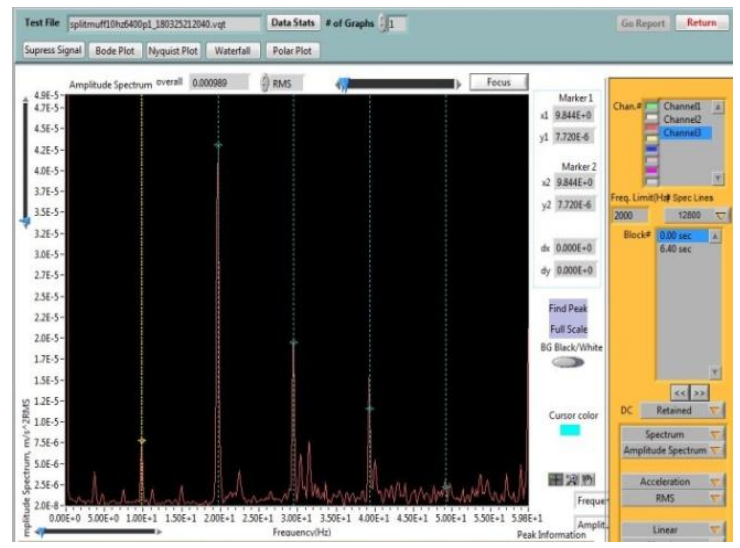

(ii) Non Driving End

(c) Split Muff coupling vibration spectrum

Figure 4(a) Vibration Spectrums at $10 \mathrm{~Hz}$

\section{$B$. Vibration spectrum at $15 \mathrm{~Hz}$}

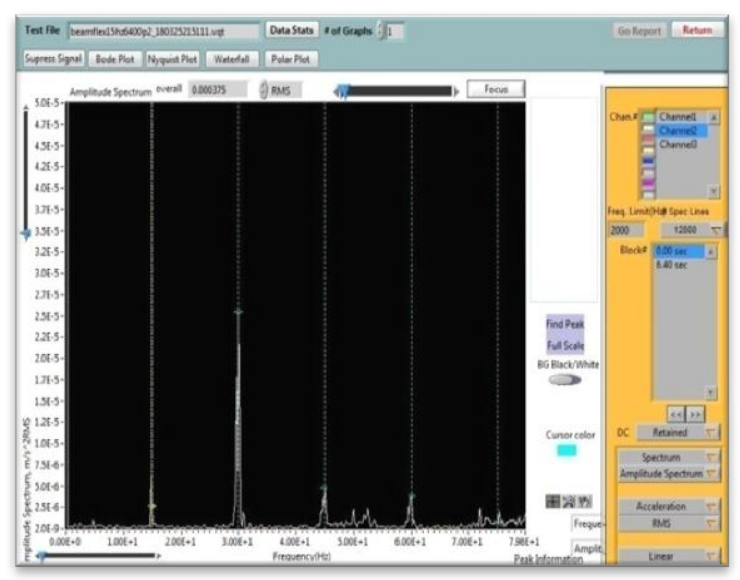

(i) Driving End

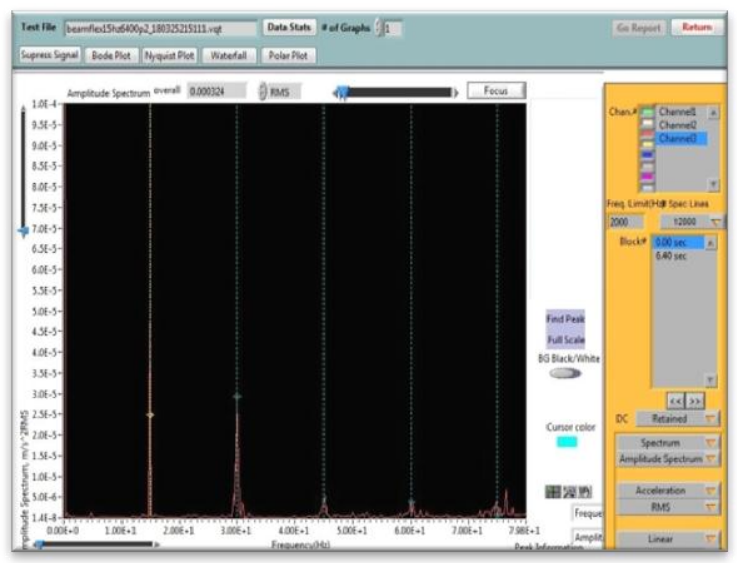

(ii) Non Driving End (a) Beam Coupling vibration spectrum

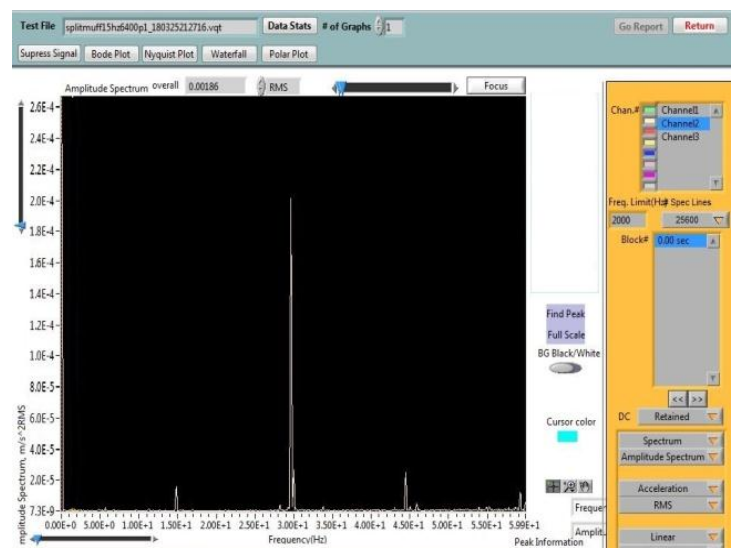

(i) Driving End

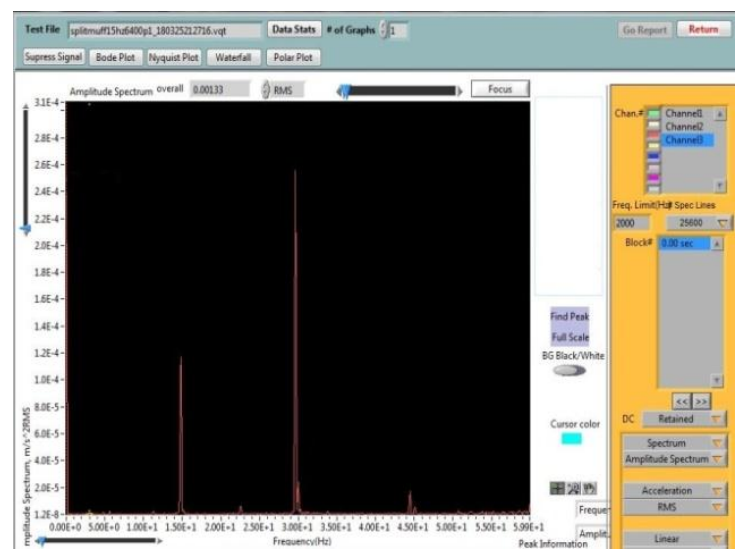

(i) Non Driving End

(b) Split muff Coupling vibration spectrum

Figure 4(b) Vibration Spectrums at $15 \mathrm{~Hz}$

C. Vibration spectrum at $20 \mathrm{~Hz}$.

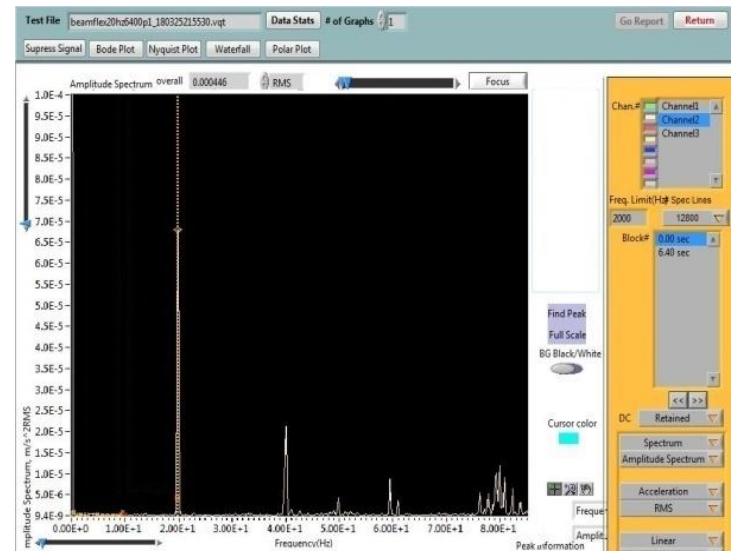

(i) Driving End 
International Journal of Engineering Applied Sciences and Technology, 2019

Vol. 4, Issue 1, ISSN No. 2455-2143, Pages 86-93

Published Online May 2019 in IJEAST (http://www.ijeast.com)

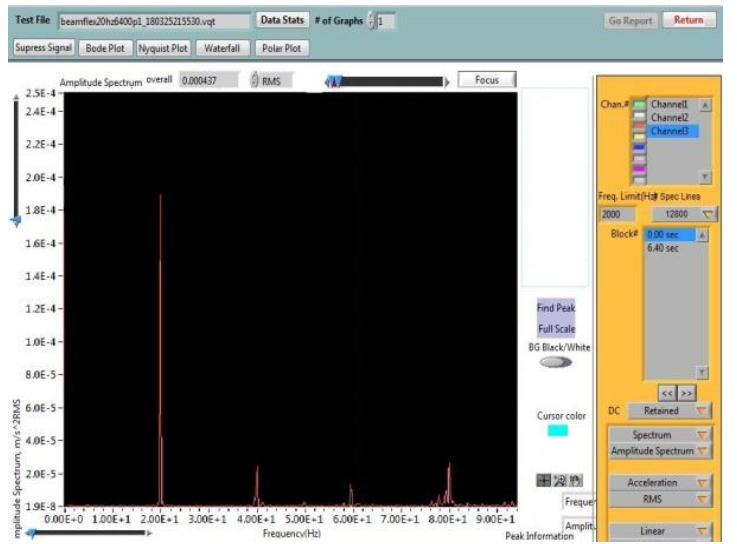

(ii) Non Driving End

(a) Beam Coupling vibration spectrum

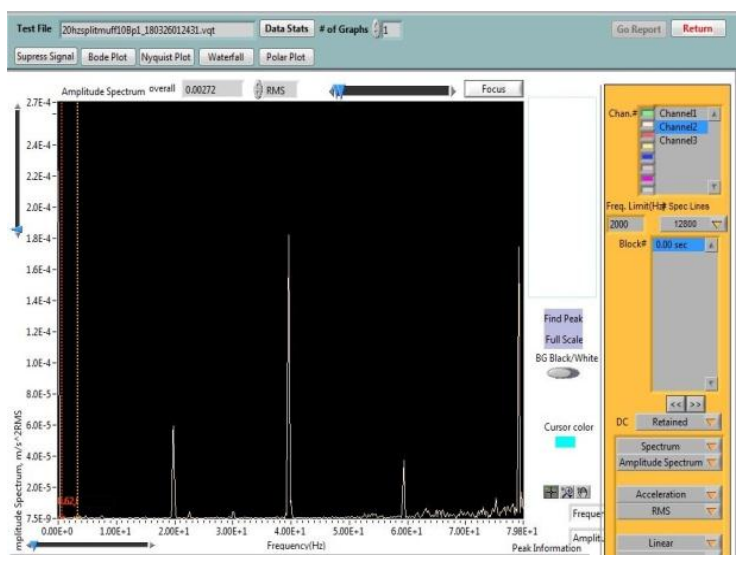

(i) Driving End

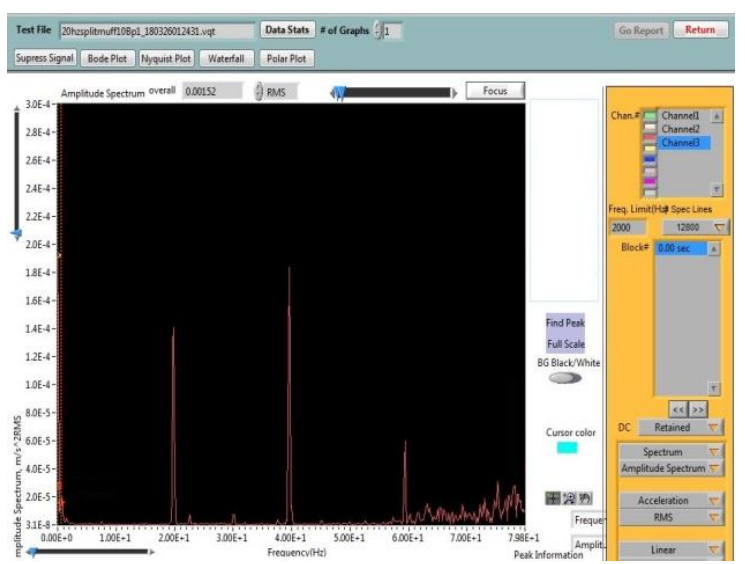

(ii) Non Driving End

(c) Split muff Coupling vibration spectrum

Figure 4(c) Vibration Spectrums at $20 \mathrm{~Hz}$
D. Tabular Representation of Results

\begin{tabular}{|c|c|c|}
\hline COUPLINGS & $\begin{array}{c}\text { DE } \\
\text { VIBRATIONS } \\
\text { mm/sec }^{2}\left(\mathbf{x 1 0 ^ { - 3 }}\right)\end{array}$ & \begin{tabular}{|c} 
NDE \\
VIBRATIONS \\
mm/sec $^{2}\left(\mathbf{x 1 0}^{-3}\right)$
\end{tabular} \\
\hline & 2X Amplitude & 2X Amplitude \\
\hline BEAM & 3.78 & 4.01 \\
\hline $\begin{array}{l}\text { SPLIT } \\
\text { MUFF }\end{array}$ & 7.87 & 43.09 \\
\hline
\end{tabular}

Table 1 Comparison of vibration amplitude of Coupling at $10 \mathrm{~Hz}$

\begin{tabular}{|c|c|c|}
\hline COUPLINGS & 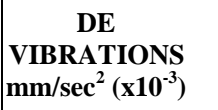 & $\begin{array}{c}\text { NDE } \\
\text { VIBRATIONS } \\
\text { mm/sec }^{2}\left(\mathbf{x 1 0}^{-3}\right)\end{array}$ \\
\hline & 2X Amplitude & 2X Amplitude \\
\hline BEAM & 25.5 & 29.36 \\
\hline $\begin{array}{l}\text { SPLIT } \\
\text { MUFF }\end{array}$ & 183.5 & 231.9 \\
\hline
\end{tabular}

Table 2 Comparison of vibration amplitude of Coupling at $15 \mathrm{~Hz}$

\begin{tabular}{|c|c|c|}
\hline COUPLINGS & $\begin{array}{c}\text { DE } \\
\text { VIBRATIONS } \\
\mathrm{mm}^{2} \sec ^{2}\left(\mathbf{x 1 0}^{-3}\right)\end{array}$ & $\begin{array}{c}\text { NDE } \\
\text { VIBRATIONS } \\
\mathrm{mm}^{2} \sec ^{2}\left(\mathrm{x10}^{-3}\right)\end{array}$ \\
\hline & 2X Amplitude & 2X Amplitude \\
\hline BEAM & 20.0 & 24.1 \\
\hline $\begin{array}{l}\text { SPLIT } \\
\text { MUFF }\end{array}$ & 174.0 & 183.5 \\
\hline
\end{tabular}

Table 3 Comparison of vibration amplitude of Coupling at $20 \mathrm{~Hz}$ 


\section{International Journal of Engineering Applied Sciences and Technology, 2019 \\ Vol. 4, Issue 1, ISSN No. 2455-2143, Pages 86-93 \\ Published Online May 2019 in IJEAST (http://www.ijeast.com)}

\section{DISCUSSION}

As the perfect alignment and balance cannot be achieve in practice, thus a case study is presented, which identifies the better coupling among the two. The coupling which absorbs more vibrations is the best coupling. For misalignment our concerned is $2 \mathrm{X}$ amplitude, because it has a greater effect of misalignment.

For figure 4(a) there are graphs which display the vibration spectrum of both the couplings at driving as well as non driving end at $10 \mathrm{~Hz}$ where one can see the cluster of vibrations amplitude occurring frequently at $\mathrm{DE}$ than NDE this may be due to the fact that lower disturbances may have died while reaching to NDE. Other than this one can observe that beam coupling is having lower 2X amplitude as compared to the split muff coupling at both ends. NDE is having comparatively higher vibrations than DE.

For figure 4(b) the graphs associated display the vibration spectrum of both the couplings at driving as well as non driving end at $15 \mathrm{~Hz}$, here clusters are lost and we are getting vibrations at $1 \mathrm{X}, 2 \mathrm{X}$ and so on. Here $2 \mathrm{X}$ amplitudes are higher than other which is clearly due to the misalignment ${ }^{[3]}$ \& ${ }^{[8]}$. Here again NDE is having comparatively higher vibrations than $\mathrm{DE}$ and Beam coupling is showing better result than split Muff.

For figure 4(c) graphs represent vibration spectrum of both the couplings at driving as well as non driving end at 20 $\mathrm{Hz}$, Beam coupling is having lower vibration amplitude than Split Muff coupling. One should observe the significant rise in $1 \mathrm{X}$ amplitude of Beam coupling which may be due to random unbalance.

The $2 \mathrm{X}$ vibration amplitude of Beam Coupling is lowest at lower speed and increases to an extent and then started falling.

Rigid Coupling showed initially a rise then a fall in the vibration of said amplitude with increase in speed.

To validate, our result came out to be in the same nature as found/published by Khot and Pallavi(2015). Other than this the work of Prajapati and Parey(2016) shows the same result that Beam coupling dampen the effect of vibrations more significantly than Split Muff.

\section{CONCLUSION}

The results suggests that misalignment can be characterized by second harmonics ie. $2 \mathrm{X}$ amplitude of shaft running speed. It is also seen that as excitation frequency changes, amplitude of vibration also change significantly.
From Tabular representation and the discussion made above one can easily conclude that the Split Muff Coupling is very prone to the vibrations as compared to the beam coupling as they have higher $2 \mathrm{X}$ vibration amplitude than those of beam coupling.

The vibrations came out to be in the as Split Muff coupling vibration>Beam Coupling vibration and hence we can say Beam Coupling is best for minimum vibration in context to misalignment.

\section{REFRENCES}

https://spectraquest.com/software/details/vq/

TECHNOTES, Spectra Quest Inc., A Study of Shaft alignment

Khot S.M., and Khaire Pallavi,(2015). Journal of Vibration analysis, Measurement and control Vol.3 No 2 pp. 165-173

Woodcock J.S., (1977) Proceedings of the International Conference on Flexible Couplings, University of Sussex, Brighton, U.K. Farnham, U.K.: Michael Neale and Associates Ltd., E1-1-E1-20. The effect of couplings upon the vibration of rotating machinery

Lees A.W., (2007) Misalignment in rigidly coupled rotor, Journal of Sound and Vibration 305 261-271.

Dewell D.W., and Mitchell L.D., (1984) American Society of Mechanical Engineers Journal of Vibration, Acoustics, Stress, and Reliability in Design106, 9-15. Detection of misaligned disc coupling using spectrum analysis.

Pandey S., and Nakra B.C., (2011) International Journal of Engineering Science and Technology Vol.3 No.4 25592572, Vibration Monitoring of a rotor system using RMS acceleration

Prajapati Ronak, and Parey Anand, (2016), Effect of Coupling Types on Rotor Vibration, can be viewed at surveillance9.sciencesconf.org

Hariharan V., and Srinivasan P.S.S., (2010) Vibration analysis of flexible coupling by considering unbalance, World applied sciences journal (8).

Hariharan V., and Srinivasan P.S.S. (2011). Vibration analysis of parallel misaligned shaft with ball bearing system, Songklanakarin Journal of Science and Technology, 33 (1), 61-68

Piotrowski J., (1986) Shaft Alignment Handbook. New 
York and Basel: Marcel Dekker, Inc.

Sekhar A.S., and Chandra Shekhar Reddy M.,(2014) Detection and Monitiring of Coupling Misalignment using Torque Techniques, Measurement 61, 111-122

https://shodhganga.inflibnet.ac.in/bitstream/10603/9878/1 0/10_chapter\%205.pdf

Kumar Sanjeev, (2015) Vibration Signature Analysis of 4 Jaw Flexible Coupling Considering Misalignment in Two Planes, IRJET, Volume 2, Issue 01 